\title{
Determination of Pheophytinatoiron(III) Chlorides by Reversed Phase High Performance Liquid Chromatography
}

\author{
Kenji Furuya, Hidenari Inoue and Tsuneo ShiraI \\ Faculty of Science and Technology, Keio University, Hiyoshi, Yokohama 223
}

\begin{abstract}
A simple and accurate HPLC method was developed for the determination of pheophytinatoiron(III) chloride (PheoFeCl) prepared by the replacement of magnesium(II) in chlorophyll [pheophytinatomagnesium(II)] with iron(III). The good separation of PheofeCl was obtained by using a stationary phase of $\mathrm{C}_{18}$ chemically bonded to silica gel and a mobile phase of acetone-acetonitrile (50:50, v/v). A tailing of the $\mathrm{PheofeCl}$ peak due to the dissociation of ion pairs was improved by addition of tetramethylammonium chloride to the mobile phase. The spectrophotometric method was also used for a comparison to the HPLC method. For the synthetic samples prepared by mixing (pheophytinato a)iron(III) chloride [(Pheo-a)FeCl] and (pheophytinato b) iron(III) chloride [(Pheo-b)$\mathrm{FeCl})$, analytical values by the spectrophotometric method were extremely high compared to those by the HPLC method because of interferences from the absorption of coexistent pigments. In the proposed HPLC method, (Pheo-a) FeCl and (Pheo-b) FeCl could be determined in the concentration range of $0.025-30 \mu \mathrm{g} \mathrm{cm}^{-3}$ and $0.06-$ $30 \mu \mathrm{g} \mathrm{cm}^{-3}$ with relative standard deviations $(n=10)$ of $6.2 \%$ and $18 \%$, respectively.
\end{abstract}

Keywords Pheophytinatoiron(III) chloride, pheophytin, chlorophyll, high performance liquid chromatography, absorption spectrophotometry

Metallochlorophylls, chlorophyll derivatives in which magnesium is replaced by other metal ions, are relatively stable to light. As metallochlorophylls with copper and zinc ions have especially high light-stability, sodium chlorophyllins of these metallochlorophylls are utilized as food additives. ${ }^{1}$ Recently, the application to the intensifier of the electrodes for photoelectron conversion $^{2}$ and the use for medicine ${ }^{3}$ have been investigated in some kinds of metallochlorophylls.

The spectrophotometric method has been widely used for the determination of chlorophyll, pheophytin and their derivatives. ${ }^{4}$ However, if chlorophyll derivatives or their degradation products coexist with metallochlorophylls, the spectrophotometric method cannot afford an accurate determination because the spectroscopic characteristics of the chlorin of these chlorophylls are similar to one another. Therefore, an accurate determination by the derivative fluorometry has been reported as an improvement of the spectrophotometric determination of chlorophylls. ${ }^{5}$ On the other hand, the rapid and simple determination of chlorophylls by HPLC has been developed as HPLC is coming into wide use in recent years. ${ }^{6-8}$ Although many HPLC studies on metal porphyrin compounds similar to chlorophylls have been reported ${ }^{9-11}$, there have been relatively few reports on the HPLC determination of metallochlorophylls.

In this paper, an HPLC method has been proposed for the determination of pheophytinatoiron(III) chlo- rides (PheoFeCl) in which magnesium(II) is replaced by iron(III). An adequate separation for the determination has been attained using a reversed phase column. A tailing of $\mathrm{PheoFeCl}$ peaks due to the dissociation of chloride ion has been reduced by addition of tetramethylammonium chloride to the mobile phase. The experimental results given here have demonstrated that the HPLC method is very useful for the rapid determination of $\mathrm{PheoFeCl}$ even in the coexistence of chlorophyll derivatives or their degradation products.

\section{Experimental}

\section{Preparation of (pheophytinato a)iron(III) chloride}

Pheophytin a (Pheo-a) was prepared from chlorophyll a (Chl-a) (Wako Pure Chemical Industries, Tokyo) by addition of $0.1 \mathrm{~mol} \mathrm{dm}^{-3}$ hydrochloric acid to an acetone solution of $\mathrm{Chl}-\mathrm{a}$ and keeping the acidified reaction mixture at $40^{\circ} \mathrm{C}$ for $30 \mathrm{~min}$. (Pheophytinato a) iron(III) chloride [(Pheo-a) $\mathrm{FeCl}]$ was prepared by refluxing a mixture of Pheo-a dissolved in acetone and iron(II) chloride-tetrahydrate (E. Merck, Darmstadt) dissolved in methanol with stirring at $60^{\circ} \mathrm{C}$ for $3 \mathrm{~h}$.

\section{Preparation of (pheophytinato b)iron(III) chloride}

Chlorophyll was extracted from spinach by the standard procedure. ${ }^{12}$ Pheophytin was prepared from 
chlorophyll by pheophytinization using hydrochloric acid, and pheophytin b (Pheo-b) was obtained from pheophytin with a reversed phase preparative column.

(Pheophytinato b)iron(III) chloride [(Pheo-b)FeCl] was prepared by refluxing a mixture of Pheo-b dissolved in chloroform and iron(II) acetate (Strem Chemicals, Inc., Newburyport) dissolved in glacial acetic acid with stirring at $60^{\circ} \mathrm{C}$ for $30 \mathrm{~h}$.

All operations described above were carried out in the dark under an atmosphere of nitrogen. The formation and purity of (Pheo-a) FeCl and (Pheob) $\mathrm{FeCl}$ were checked by HPLC. The purification of all products was carried out using a reversed phase preparative column. All chemicals were of reagent grade and solvents for the mobile phase were of HPLC grade (Kanto Chemical Co., Tokyo).

\section{Apparatus}

The HPLC apparatus used was a Nippon Bunko (Jasco) BIP-I equipped with a Rheodyne 7125 syringeloading sample injector (20 $\mathrm{mm}^{3}$ loop) and a Finepak Sil $\mathrm{C}_{18} \mathrm{~S}$ column $(150 \mathrm{~mm} \times 4.6 \mathrm{~mm}$ i.d., Jasco). For preparative HPLC, a KV-3W sample injector $(600$ $\mathrm{mm}^{3}$ loop, Kusano Kagakukikai Co., Tokyo) and a Develosil ODS column $(32 \mathrm{~cm} \times 3 \mathrm{~cm}$ i.d., Nomura Chemical Co., Aichi) were used. UVIDEC-100-III (Jasco) was used for a UV-visible detector. The flow rate of mobile phase was $0.7 \mathrm{~cm}^{3} \mathrm{~min}^{-1}$ and the column temperature was ambient $\left(20^{\circ} \mathrm{C}-28^{\circ} \mathrm{C}\right)$. Absorption spectra were recorded with a UVIDEC-I spectrophotometer (Jasco) using $1 \mathrm{~cm}$ silica cells.

\section{Results and Discussion}

\section{Preparation of (Pheo-a) FeCl and (Pheo-b) FeCl}

(Pheo-a) $\mathrm{FeCl}$ could be obtained by refluxing a mixture of Pheo-a dissolved in acetone and iron(II) chloride-tetrahydrate dissolved in methanol. However, the preparation of (Pheo-b) $\mathrm{FeCl}$ was unsuccessful under the same conditions as those for (Pheo-a)FeCl. The structural difference between (Pheo-a) $\mathrm{FeCl}$ and

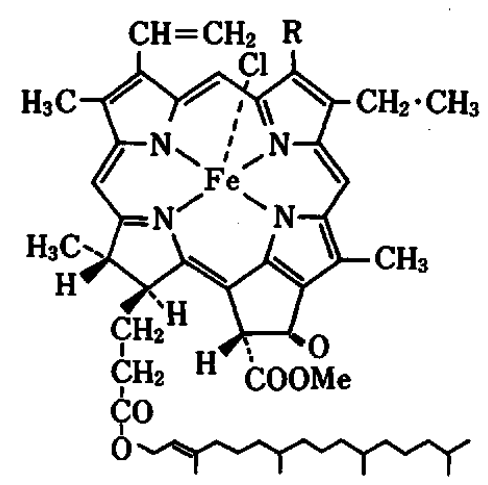

Fig. 1 Structures of pheophytinatoiron(III) chlorides. $\mathrm{R}=$ $\mathrm{CH}_{3}$, (Pheo-a)FeCl; $\mathrm{R}=\mathrm{CHO}$, (Pheo-b)FeCl.
(Pheo-b)FeCl is that (Pheo-a) $\mathrm{FeCl}$ has a methyl group and (Pheo-b) FeCl an aldehyde group on $\mathrm{R}$ in Fig. 1 . Since the aldehyde group has higher polarity than the methyl one, water molecules in the reaction system were expected to prevent the production of (Pheob) FeCl. Therefore, anhydrous iron(II) chloride dissolved in methanol or $N, N$-dimethylformamide was used for the preparation. However, the formation of (Pheo-b) FeCl was not confirmed, but degradation products were yieled. Iron(II) acetate anhydride which is a common reagent for metal porphyrin chelates ${ }^{13}$ was tried to use as another anhydrous iron(II) salt. Fortunately, (Pheo-b)FeCl was formed by refluxing a mixture of Pheo-b dissolved in chloroform and iron(II) acetate anhydride dissolved in glacial acetic acid at $60^{\circ} \mathrm{C}$ for $30 \mathrm{~h}$. It was ascertained by HPLC that unreacted Pheo-b still remained in the reaction mixture after the reaction. Although the production of (Pheob) $\mathrm{FeCl}$ increased with the elongation of the reaction time, degradation products also increased with time. The reaction temperature over $60^{\circ} \mathrm{C}$ has accelerated degradation of Pheo-b under the present experimental conditions. Therefore, a reaction time of $30 \mathrm{~h}$ and a reaction temperature of $60^{\circ} \mathrm{C}$ have been regarded as being adequate. Iron ions in (Pheo-a) FeCl and (Pheob) $\mathrm{FeCl}$ are trivalent because they are oxidized during the preparation. ${ }^{14}$ The chloride ion is weakly coordinated to the central iron(III) ion to form an ion pair. The trivalent state of the central iron ion in $\mathrm{PheoFeCl}$ is more stabilized compared to its divalent state as in iron(III) complexes of porphyrins. ${ }^{15}$

\section{HPLC conditions and effect of addition of salt to mobile phase}

Chlorophylls, including (Pheo-a) $\mathrm{FeCl}$ and (Pheob) $\mathrm{FeCl}$, are constituted of the chlorin having hydrophilic groups and the hydrophobic phytol one (cf. Fig. 1). In view of the amphipatic nature of chlorophylls, the reversed phase column was expected to be appropriate. Preliminary tests by thin-layer chromatography revealed that the most suitable $R_{f}$ value is achieved by a stationary phase of $\mathrm{C}_{18}$ chemically bonded to silica gel. Thus, Finepak Sil $\mathrm{C}_{18} \mathrm{~S}$ was selected to use for an HPLC column. The mobile phase was examined to obtain good separation and retention using binary components such as acetone-acetonitrile, acetone-methanol and methanol-acetonitrile, and ternary component like acetone-acetonitrile-methanol. Of these binary and ternary components, acetone-acetonitrile $(50: 50, v / v)$ was the best for the separation and retention of $\mathrm{PheoFeCl}$.

Under the HPLC conditions described above, tailings appeared on the peaks of $\mathrm{PheoFeCl}$ besides Chl-a, Chl-b, Pheo-a and Pheo-b. The mixing ratio of the mobile phases was varied and the column temperature was elevated. However, these efforts were unsuccessful in reducing the tailing of peaks. Since no tailing appeared on the peaks of metallochlorophylls with divalent metals such as copper(II) chlorophyll 
[pheophytinatocopper(II)], zinc(II) chlorophyll[pheophytinatozinc(II)] ${ }^{16}$ and nickel(II) chlorophyll[pheophytinatonickel(II)], it was assumed to be caused by the dissociation of chloride ions of $\mathrm{PheoFeCl}$ in the mobile phase. Tetramethylammonium chloride was added to the mobile phase so as to inhibit the dissociation of chloride ions. As shown in Fig. 2, the degree of tailing was reduced with the increasing concentration of tetramethylammonium chloride in the range of $10^{-5} \mathrm{~mol} \mathrm{dm}^{-3}$ to $10^{-2} \mathrm{~mol} \mathrm{dm}$. In practice, the concentration of the salt added was $10^{-3} \mathrm{~mol} \mathrm{dm}^{-3}$ because it was difficult to dissolve the salt in the mobile phase at a concentration higher than $10^{-2} \mathrm{~mol} \mathrm{dm}^{-3}$. A reasonable interpretation of appearance of tailings is that the cation complexes resulting from the dissociation of chloride ions are retained to the residual silanols on the stationary phase by an ion exchange interaction.

The relationship between the concentration of tetramethylammonium chloride and the capacity factors $\left(k^{\prime}\right)$ of $(\mathrm{Pheo}-\mathrm{a}) \mathrm{FeCl}$, Pheo-a and Pheo-b is shown in Fig. 3. The $k^{\prime}$ values of Pheo-a and Pheo-b which have no counter anions are independent of the concentration of the salt. The $k^{\prime}$ values of (Pheoa) $\mathrm{FeCl}$ also seem to be constant, although (Pheoa) $\mathrm{FeCl}$ has a counter anion. In this case, the $k^{\prime}$ value of (Pheo-a)FeCl was calculated from the position of the top of (Pheo-a)FeCl peak whether it had a tailing or not. Indeed, there is a strong presumption that the true $k^{\prime}$ value obtained by correcting the tailing should be related to the concentration of the salt when the dependence of tailings on the concentration of the salt is taken into account.

A typical chromatogram obtained under the HPLC conditions described above is shown in Fig. 4.

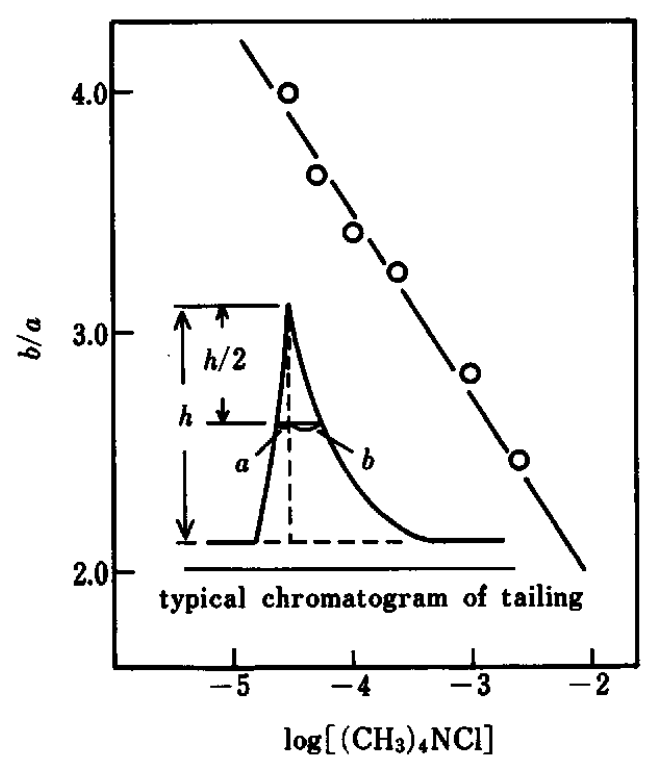

Fig. 2 Dependence of the tailing of chromatogram on the concentration of $\left(\mathrm{CH}_{3}\right)_{4} \mathrm{NCl}$.
Unreacted Pheo-a and Pheo-b still remain in the synthetic sample of (Pheo-a) $\mathrm{FeCl}$ and (Pheo-b) FeCl. (Pheo-a) FeCl, diastereoisomer of (Pheo-a) FeCl, was found to be formed by epimerization. ${ }^{17}$ The polar solvent in the reaction solution promotes the epimerization.

\section{Absorption spectra}

Absorption spectra of (Pheo-a)FeCl and (Pheob) $\mathrm{FeCl}$ are similar to those of chlorophylls because the spectroscopic characteristics originating from the chlorin are common to them. Absorption spectra of (Pheo-a) FeCl, (Pheo-a) FeCl and Pheo-a are shown in Fig. 5, and those of (Pheo-b) $\mathrm{FeCl}$ and Pheo-b shown in

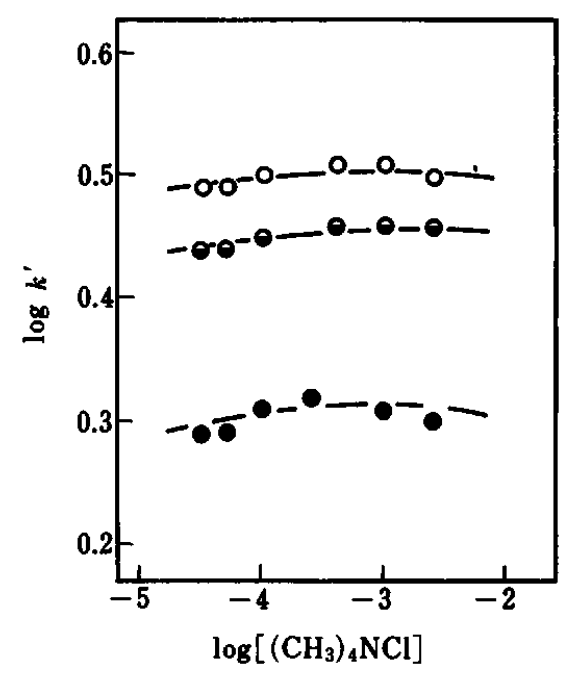

Fig. 3 Relationship between $k^{\prime}$ values of pheophytins and concentration of $\left(\mathrm{CH}_{3}\right)_{4} \mathrm{NCl}$. O, Pheo-a; $\ominus$, Pheo-b; $\bigcirc$, (Pheo-a)FeCl.

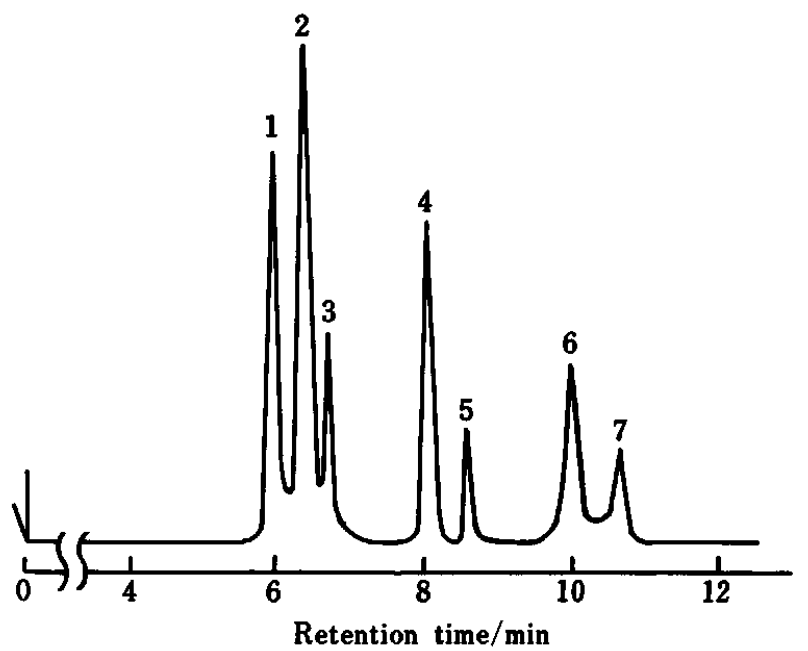

Fig. 4 Chromatogram of pheophytinatoiron(III) chlorides and pheophytins. Peaks: 1, (Pheo-b)FeCl; 2, (Pheo-a)FeCl; 3, (Pheo-a)FeCl; 4, Pheo-b; 5, Pheo-b'; 6, Pheo-a; 7, Pheo-a'. 
Fig. 6. The absorption spectrum of (Pheo-b) FeCl, diastereoisomer of (Pheo-b) FeCl, was not measured because the former could not be obtained in pure form under the preparative HPLC conditions described above. Each pigment has specific maximal absorption at the Soret and $Q$ bands. The positions of their maximal absorptions of (Pheo-a)FeCl and (Pheob) $\mathrm{FeCl}$ are close to one another. Since the absorption maximum of coexistent pigments is located near the wavelength of maximal absorption of the object

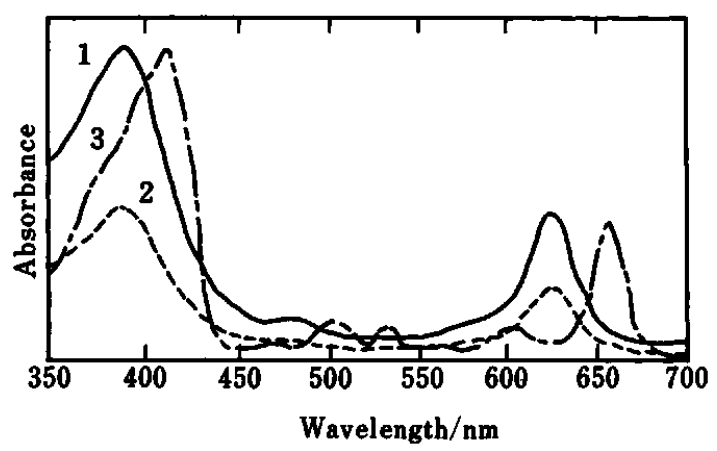

Fig. 5 Absorption spectra of (Pheo-a) $\mathrm{FeCl}$, (Pheo-a) $\mathrm{FeCl}$ and Pheo-a. 1, (Pheo-a)FeCl; 2, (Pheo-a')FeCl; 3, Pheo-a.

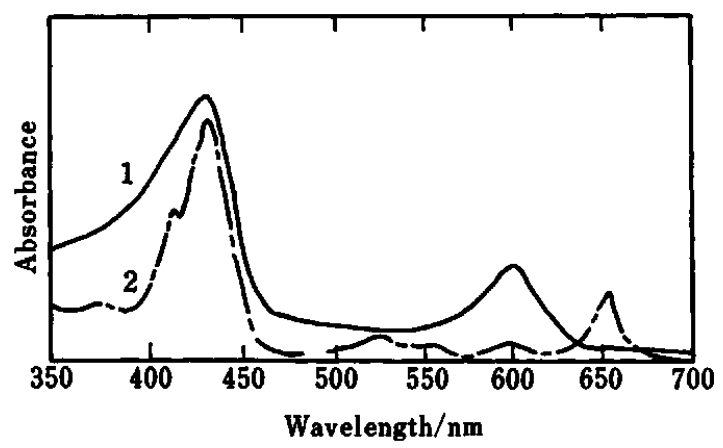

Fig. 6 Absorption spectra of (Pheo-b) FeCl and Pheo-b. 1, (Pheo-b) FeCl; 2, Pheo-b.

Table 1 Absorption maxima and molar extinction coefficients of chlorophylls and metallochlorophylls

\begin{tabular}{|c|c|c|c|c|}
\hline \multirow[b]{2}{*}{ Compound } & \multicolumn{2}{|c|}{$\lambda_{\max } / \mathrm{nm}$} & \multicolumn{2}{|c|}{$\varepsilon / 10^{4} \mathrm{~cm}^{-1} \mathrm{~mol}^{-1} \mathrm{dm}$} \\
\hline & $\begin{array}{l}\text { Soret } \\
\text { band }\end{array}$ & $\mathbf{Q}$ band & $\begin{array}{c}\lambda_{\max } \text { at } \\
\text { Soret band }\end{array}$ & $\begin{array}{l}\lambda_{\max } \text { at } \\
Q \text { band }\end{array}$ \\
\hline Chlorophyll a & 433 & 663 & $10.0^{b}$ & $8.1^{b}$ \\
\hline Chlorophyll b & 465 & 650 & $13.6^{b}$ & $4.8^{b}$ \\
\hline Pheo-a & 410 & 666 & $9.4^{\mathrm{a}}$ & $4.2^{a}$ \\
\hline Pheo-b & 435 & 655 & $15.3^{b}$ & $2.9 \mathrm{~b}$ \\
\hline (Pheo-a)FeCl & 396 & 625 & $6.2^{\mathrm{a}}$ & $3.2^{\mathrm{a}}$ \\
\hline (Pheo-b)FeCl & 431 & 609 & $5.1^{\mathrm{a}}$ & $1.7^{\mathrm{a}}$ \\
\hline
\end{tabular}

a. Solvent : acetone/acetonitrile $(50 / 50)$ containing $10^{-3}$ $\mathrm{M}\left(\mathrm{CH}_{3}\right)_{4} \mathrm{NCl}$.

b. Taken from Reference 4 where the solvent is acetone. compound for analysis, an accurate determination of (Pheo-a) FeCl and (Pheo-b) $\mathrm{FeCl}$ by the spectrophotometric method is difficult. The wavelengths of maximal absorptions and the molar extinction coefficients $(\varepsilon)$ of the Soret and $Q$ bands of each pigment are summarized in Table 1. The wavelengths of maximal absorptions are shifted to the shorter wavelength both at the Soret band and at the $Q$ band on the replacement of magnesium(II) in chlorophyll by iron(III). It is reported that this blue shift occurs in a similar manner when magnesium(II) is replaced by copper(II)..$^{18}$

\section{Calibration curves}

The calibration curves for (Pheo-a) FeCl and (Pheob) $\mathrm{FeCl}$ constructed by using the peak height method were linear over the concentration range of 5-30 $\mu \mathrm{g}$ $\mathrm{cm}^{-3}$. The peak of (Pheo-a) FeCl and (Pheo-b) FeCl were decreased due to epimerization to their stereoisomer, (Pheo-a') $\mathrm{FeCl}$ and $\left(\mathrm{Pheo}^{\prime} \mathrm{b}^{\prime}\right) \mathrm{FeCl}$, in solution, respectively. In particular, this phenomenon was remarkable with (Pheo-b) $\mathrm{FeCl}$ and its peak height was reduced to half in $\mathbf{5} \mathrm{h}$ after preparation of the solution. In order to keep the linearity of a calibration curve, measurement should be done as soon as possible after the preparation of standard solutions. Detection limits of (Pheo-a) FeCl and (Pheo-b) FeCl by the HPLC method were $25 \mathrm{ng} \mathrm{cm}^{-3}$ and $60 \mathrm{ng} \mathrm{cm}^{-3}$, respectively. The relative standard deviations $(n=10)$ of the determination of (Pheo-a) FeCl and (Pheo-b) FeCl were $6.2 \%$ and $18 \%$, respectively. The large relative standard deviation of the latter seems to be ascribed to a decrease of the peak height by rapid epimerization. On the other hand, (Pheo-a) $\mathrm{FeCl}$ and (Pheo-b) $\mathrm{FeCl}$ could be spectrophotometrically determined by measuring the maximal absorption at the Soret band [(Pheo-a)FeCl: $392 \mathrm{~nm}$, (Pheo-b)FeCl: $431 \mathrm{~nm}$ ] and the $\mathrm{Q}$ band [(Pheo-a)FeCl: $626 \mathrm{~nm}$, (Pheo-b)FeCl: $609 \mathrm{~nm}$ ]. A linearity of calibration curves using the Soret and $Q$ bands was kept over the concentration range of 5-30 $\mu \mathrm{g} \mathrm{cm}^{-3}$ of (Pheo-a) FeCl and (Pheo-b) FeCl.

Determination of (Pheo-a) FeCl and (Pheo-b) FeCl by HPLC method and spectrophotometric method

Synthetic samples prepared by mixing (Pheo-a) FeCl and (Pheo-b) $\mathrm{FeCl}$ were assayed by using the calibration curves of the HPLC and spectrophotometric methods. The analytical results obtained are summarized in Table 2. The mixing ratio of (Pheo-a) FeCl and (Pheo-b) $\mathrm{FeCl}$ is unknown for Sample A-Sample $\mathrm{C}$ in which pheophytins or degradation products are contained. The mixing ratio of Sample D-Sample F is known because they were prepared from pure (Pheoa) $\mathrm{FeCl}$ and (Pheo-b) FeCl. Analytical values of (Pheoa) FeCl and (Pheo-b) FeCl by the HPLC method are closer to the calculated contents of synthetic samples compared with those by the spectrophotometric method which gave enormously high values. The HPLC analytical values for Sample E and Sample F, 
Table 2 Analytical values by the HPLC and spectrophotometric methods

\begin{tabular}{|c|c|c|c|c|}
\hline \multirow{2}{*}{ Sample } & \multicolumn{2}{|c|}{ (Pheo-a)FeCl, wt $\%$} & \multicolumn{2}{|c|}{ (Pheo-b)FeCl, wt $\%$} \\
\hline & HPLCa & Spec. & HPLC a & Spec. \\
\hline $\mathbf{A}$ & 3.5 & 14.6 & 3.6 & 13.0 \\
\hline B & 2.7 & 12.9 & 3.3 & 12.5 \\
\hline C & 3.7 & 17.5 & 4.4 & 14.8 \\
\hline D & $55.8(52.5)^{b}$ & 63.0 & $41.7(47.5)^{b}$ & 71.8 \\
\hline $\mathbf{E}$ & $32.7(26.9)$ & 45.3 & $63.0(73.1)$ & 86.8 \\
\hline $\mathbf{F}$ & $18.6(10.9)$ & 34.5 & $73.8(89.1)$ & 95.4 \\
\hline
\end{tabular}

a. Detected at $396 \mathrm{~nm}$ [(Pheo-a)FeCl] and $431 \mathrm{~nm}$ [(Pheo-b)FeCl].

b. Values in parentheses are those calculated.

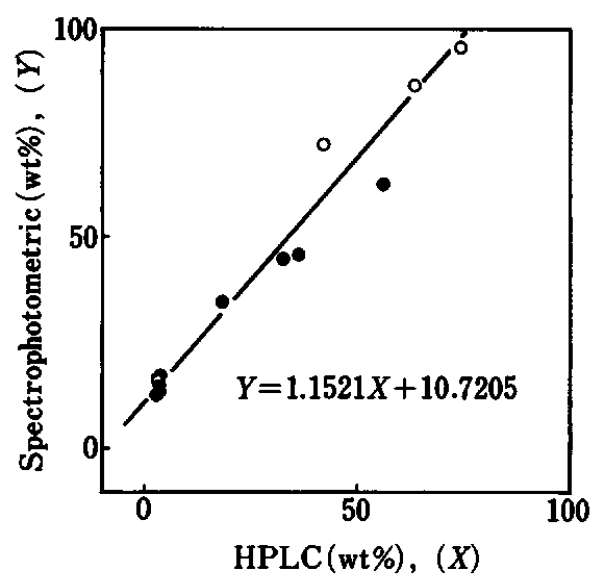

Fig. 7 Plots of analytical values by spectrophotometric method against those by HPLC method. (Pheo-a)FeCl; O, (Pheo-b)FeCl.

both of which contain a great deal of (Pheo-b) FeCl, are not close to the calculated values. This is considered to be caused by a partial overlap of a (Pheo-b) FeCl peak to a (Pheo-a) FeCl peak because both compounds have a close retention time with each other under the present analytical conditions. The overestimation by the spectrophotometric method is attributable to the fact that the absorption bands of pheophytins or degradation products overlap partially with those of (Pheoa) $\mathrm{FeCl}$ and (Pheo-b)FeCl (cf. Figs. 5 and 6). Therefore, the accurate determination of (Pheo-a)FeCl and (Pheo-b) FeCl by the spectrophotometric method is difficult due to interferences by the absorption of coexistent pigments at the measuring wavelengths. The analytical values obtained by the spectrophotometric method are plotted against those by the HPLC method. As shown in Fig. 7, a straight line does not pass through the origin. The determinations by the spectrophotometric method were achieved by measuring maximal absorptions at the $Q$ band of
PheoFeCl. ${ }^{4}$ The analytical values using the Soret band are higher than those using the $Q$ band because the wavelengths of maximal absorption of chlorophyll derivatives or their degradation products are much closer to each other at the Soret band than at the $Q$ band.

In conclusion, the analytical values of $\mathrm{PheoFeCl}$ determined by the spectrophotometric method are higher than those by the HPLC method. This is a common problem to determinations of not only PheoFeCl but also chlorophylls and their derivatives which have similar patterns of absorption spectra. The determination of $\mathrm{PheoFeCl}$ by the HPLC method proposed here is expected to be applicable to other metallochlorophylls or their derivatives.

\section{References}

1. M. Ishidate and A. Tanimura, "Shokuhintenkabutsu kouteisho-kaisetsusho", B-655, B-678, Hirokawa Shoten, Tokyo (1979).

2. T. Watanabe, M. Yamamoto and K. Honda, Proceedings of the 45th Annual Meeting of the Chemical Society of Japan, p. 565 (1982).

3. M. Sato, I. Fujimoto, T. Sakai, R. Kimura and T. Murata, Yakugaku Zasshi, 99, 1055 (1979).

4. L. P. Vernon, Anal. Chem., 32, 1144 (1960).

5. Y. Yoshitake, S. Gohda, H. Yamazaki, K. Morishige, Y. Nishikawa and T. Shigematsu, Bunseki Kagaku, 33, 667 (1984).

6. T. Braumann and L. H. Grimme, Biochim. Biophys. Acta, 637, 8 (1981).

7. L. M. Brown, B. T. Hargrave and M. D. Mackinnon, Can. J. Fish. Aquat. Sci., 38, 205 (1981).

8. T. Watanabe, A. Hongu, K. Honda, M. Nakazato, M. Konno and S. Saitoh, Anal. Chem., 56, 251 (1984).

9. V. Miller and L. Malina, J. Chromatogr., 145, 290 (1978).

10. S. Igarashi, T. Hashimoto, Y. Matsumoto and T. Yotsuyanagi, Bunseki Kagaku, 32, 591 (1983).

11. K. Saitoh, K. Hirano and N. Suzuki, Proceedings of the 47th Symposium on Analytical Chemistry, p. 355 (1986).

12. K. Iriyama, M. Shiraki and M. Yoshiura, J. Liq. Chromatogr., 2, 255 (1979).

13. N. Sadasivan, H. I. Eberspaecher, W. H. Fuchsman and W. S. Caughey, Biochemistry, 8, 534 (1969).

14. J. C. Fanning, J. J. Jen and A. J. Mouchet, J. Inorg. Nucl. Chem., 38, 645 (1976).

15. T. Osa, N. Kobayashi, H. Ogoshi, H. Sugimoto, H. Kashiwagi, Y. Ookatsu, T. Iizuka and Y. Ishimura, "Porphyrin no Kagaku", pp. 55-70, Kyoritsu Shuppan, Tokyo (1982).

16. H. Inoue, M. Imai and T. Shirai, Proceedings of the 47th Symposium on Analytical Chemistry, p. 107 (1986).

17. J. J. Katz, G. D. Norman, W. A. Svec and H. H. Strain, J. Am. Chem. Soc., 90, 6841 (1968).

18. E. Dujardin, P. Laszlo and D. Sacks, J. Chem. Educ., 52, 742 (1975). 